\title{
Initial experience with topical fluorouracil (5-FU) for treatment of anal intraepithelial neoplasia (AIN) in HIV-positive patients
}

Sean M Snyder ${ }^{1 *}$, Lacey Siekas², David M Aboulafia,

From $12^{\text {th }}$ International Conference on Malignancies in AIDS and Other Acquired Immunodeficiencies (ICMAOI)

Bethesda, MD, USA. 26-27 April, 2010

\section{Background}

Exposure to certain strains of human papilloma virus (HPV) promotes dysplasia in cells of the anal canal epithelium, leading to AIN, which is in turn a precursor to squamous cell carcinoma of the anus (SCCA). Patients with HIV infection who have anoreceptive intercourse are at heightened risk for acquiring HPV, AIN, and SCCA. The use of topical 5-FU to prevent the progression of lower genital tract neoplasia to invasive cervical carcinoma has been studied in both HIV+ and HIV- women. Although intravenous 5-FU is also commonly used for treatment of invasive SCCA, there has been little experience with the use of topical 5-FU as therapy for AIN.

\section{Materials and methods}

We retrospectively reviewed medical records from our anal dysplasia clinic. Our study population comprised $11 \mathrm{HIV}+$ men with biopsy-proven AIN who were treated with topical 5-FU. All patients were initially instructed to apply a pea-sized amount of topical 5-FU to the anus each night, to wash their hands afterwards, and to wipe away excess 5-FU in the morning. Patients reduced the frequency of application if they experienced undue local irritation.

\section{Results}

Patient data are summarized in Table 1.6 of 11 (55\%) patients showed improvement in clinical appearance. Anoscopy images for one of these patients before and

\footnotetext{
*Correspondence: Sean.snyder@virginiamason.edu

'Department of Graduate Medical Education, Virginia Mason Medical Center, Seattle, WA, USA
}

Full list of author information is available at the end of the article
Table 1

\begin{tabular}{ll}
\hline Age range in years (median) & $32-67(45)$ \\
On HAART (\%) & $9(82 \%)$ \\
CD4+ cell count/ $\mathrm{LL}$ range (median) & $35-730(416)$ \\
HIV viral copies/mL range (median) & $<75-172,966(<75)$ \\
Treatment duration range (median) & $7 \mathrm{wks}-6 \mathrm{mo}(20 \mathrm{wks})$ \\
Clinically improved (\%) & $6(55 \%)$ \\
Perianal irritation (\%) & $8(73 \%)$ \\
Anal fissure (\%) & $1(9 \%)$ \\
Perianal HSV (\%) & $1(9 \%)$ \\
Decreased dosing frequency (\%) & $6(55 \%)$ \\
Discontinued (\%) & $1(9 \%)$ \\
\hline
\end{tabular}

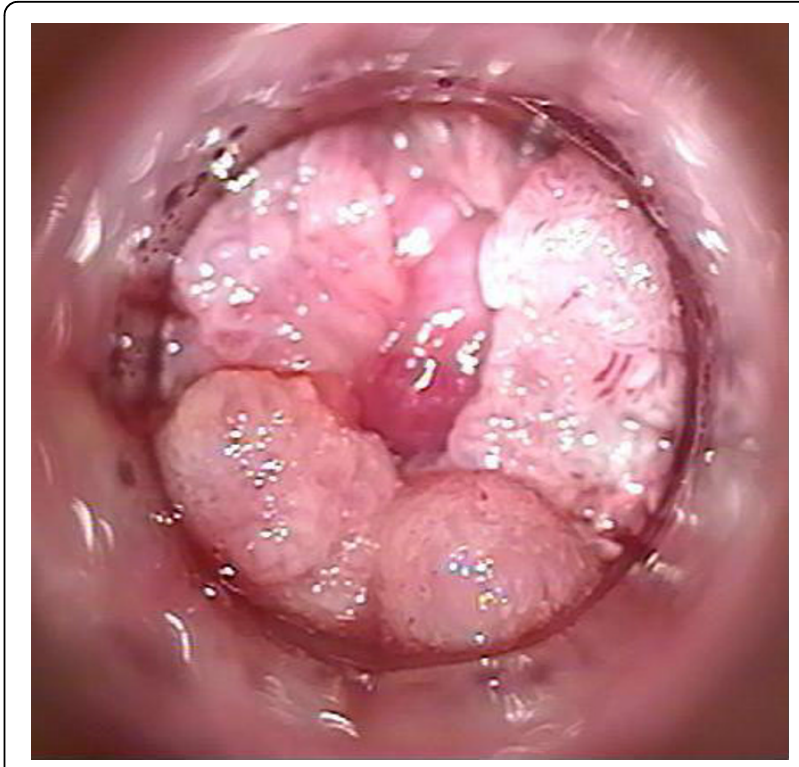

Figure 1 Before Topical 5-FU. 


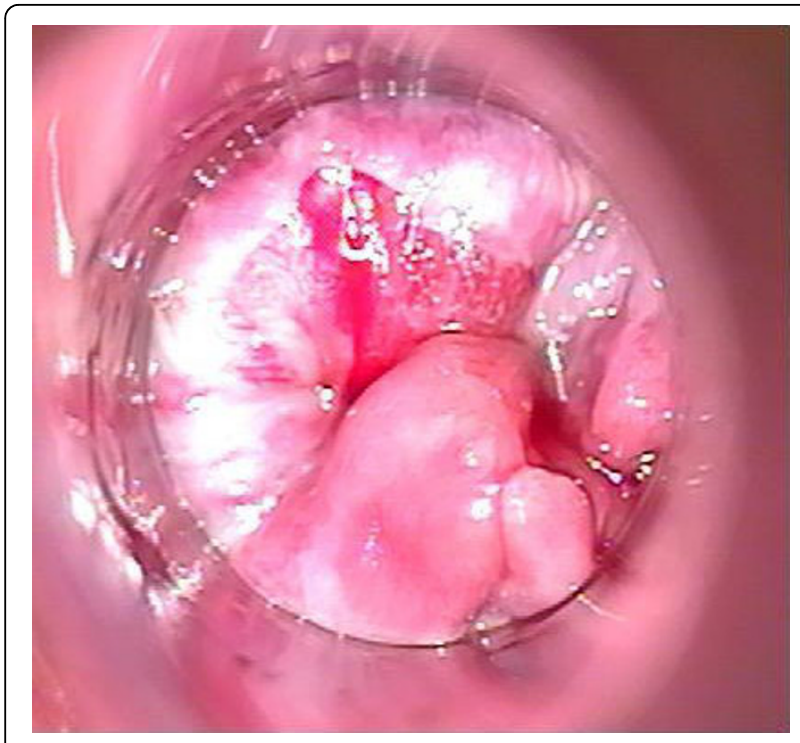

Figure 2 After Topical 5-FU.

after treatment are shown in Figures 1 and 2, respectively; note the diffusely verrucous appearance in Figure 1 (arrows).

While all patients had biopsies of the areas with the most clinically severe dysplasia pre-treatment, only 6 had biopsies post-treatment, and of those only 2 showed improvement in pathologic grade on biopsy. $6(55 \%)$ patients decreased frequency of 5-FU application due to mild to moderate perianal irritation.

\section{Conclusions}

Patients tolerated topical 5-FU without significant side effects. Our results are preliminary, but suggest a role for topical 5-FU in reducing disease burden in anal dysplasia. While this therapy may not eliminate areas with the worst dysplasia, reducing disease burden may facilitate the use of destructive modalities to treat residual areas of high-grade dysplasia.

\section{Acknowledgements}

This article has been published as part of Infectious Agents and Cancer Volume 5 Supplement 1, 2010: Proceedings of the $12^{\text {th }}$ International Conference on Malignancies in AIDS and Other Acquired

Immunodeficiencies (ICMAOI). The full contents of the supplement are available online at http://www.biomedcentral.com/1750-9378/5?issue=S1 .

\section{Author details}

'Department of Graduate Medical Education, Virginia Mason Medical Center, Seattle, WA, USA. ${ }^{2}$ Department of Gastroenterology, Virginia Mason Medical Center, Seattle, WA, USA. ${ }^{3}$ Department of Hematology and Oncology, Virginia Mason Medical Center, Seattle, WA, USA. ${ }^{4}$ Division of Hematology, University of Washington, Seattle, WA, USA.

Published: 11 October 2010
doi:10.1186/1750-9378-5-S1-A41

Cite this article as: Snyder et al: Initial experience with topical fluorouracil (5-FU) for treatment of anal intraepithelial neoplasia (AIN) in HIV-positive patients. Infectious Agents and Cancer 2010 5(Suppl 1):A41.

\section{Submit your next manuscript to BioMed Central and take full advantage of:}

- Convenient online submission

- Thorough peer review

- No space constraints or color figure charges

- Immediate publication on acceptance

- Inclusion in PubMed, CAS, Scopus and Google Scholar

- Research which is freely available for redistribution 